\title{
Design of Quadcopter Robot as a Disaster Environment Remote Monitor
}

\author{
Made Sudarma, I.B. Alit Swamardika, Adinata Mas Pratama \\ Computer System and Informatics, Departement of Electrical and Computer System Engineering \\ Faculty of Engineering, Udayana University, Bukit Jimbaran, Bali, Indonesia
}

\begin{tabular}{l} 
Article Info \\
\hline Article history: \\
Received Apr 8, 2015 \\
Revised Nov 2, 2015 \\
Accepted Nov 19, 2015 \\
\hline
\end{tabular}

Keyword:

Engineering

Flight controller

GoPro camera

Quadcopter robot

\begin{abstract}
As technology development increase, human more use robot technology to help in many fields. One of robot technology advances is the flying robot Quadcopter. The quadcopter robot is an Unmanned Aerial Vehicle or UAV that consists of four propellers and four brushless motors that function as actuator. Quadcopter was designed by using KK Board V 2.0 Flight Controller which is a series of motor rotation controller and all at once has Accelerometer censor as acceleration censor and Gyroscop censor as a balance or stability censor. The robot controlling is by using remote control (RC), and GoPro HD Hero2 camera was installed to monitor the condition of the environment. Result of testing is that the quadcopter has maximum load for $4.4 \mathrm{~kg}$ and maximum range distance of $\mathrm{RC}$ is 100 meters without any barrier and 50 meters with barrier. In the testing, robot can fly with maximum height for 30 meters from land surface. The robot is equipped with camera, so the quadcopter flying robot can be used to monitor any places that are hard to reach.
\end{abstract}

Copyright $(2016$ Institute of Advanced Engineering and Science. All rights reserved.

\section{Corresponding Author:}

Made Sudarma

Departement of Electrical and Computer System Engineering

Engineering Faculty, Udayana University

Jimbaran Campus, Kuta 80361, Bali, Indonesia, Telp./Fax. : +62361703315

Email: msudarma@unud.ac.id

\section{INTRODUCTION}

As the technology increase, robot is a technology that is developed to help human in carry out a certain task, for example a task that needs a high carefulness, high risk, a task that needs a huge power, or any monotonous tasks. In addition, it can also be used to places that are hard to reach or are dangerous for human. One of robot technology that is being developed by some countries is the flying robot, whether in the form of plane or helicopter with various types. Flying robot of helicopter type is used for the necessity that cannot be reached by human such as to monitor traffic jam, survey and mapping, spy robot, to monitor natural disaster, to monitor land fire, to assit for firing extinguishing equipment, searching media for Search and Rescue (SAR) mission, to escort the president and to monitor building construction in civil engineer field.

Recently many researchs about quadcopter robot has been done especially related to hardware design and the simulation about the stability of the quadcopter robot by using a camera that was installed to the quadcopter that function as a navigation system to the quadcopter robot so make it possible to move automatically [1]. Whereas other research design a quadcopter that is able to move by using visual flight control, where the robot can visualize the condition of its surrounding environment and then it moves based on the motion detector on the robot so make it possible to move automatically [2].

If we see from the robot technology development especially the flying robot, and the condition of Indonesia that often experience disaster and safety disturbance, then in this research it was design a flying 
robot of helicopter type with four motors and four propellers that is called quadcopter. Quadcopter was designed by using KK Board V 2.0 Flight Controller that is a series of motor rotation controller and all at once has Accelerometer censor as an acceleration censor and the Gyroscop censor as a balance or stability censor. Robot controlling is by using remote control Turnigy $2.4 \mathrm{GHz}$, and GoPro HD Hero2 camera was installed to monitor the condition of the environment, so it is expected to be able to give a solution to accelerate the searching of natural disaster victims.

\section{COMPONENTS}

\subsection{K.K. Board V 2.0 Flight Controller}

KK Board V 2.0 Flight Controller is a series of brushless motor rotation controller and all at once has Accelerometer censor as an acceleration censor and Gyroscop Censor as a stability censor. There are some flying device configurations on the KK Board V 2.0 Flight Controller. KK Board V 2.0 is also able to be reprogrammed according to the necessity of the user. Figure 1 shows that there are 6 PIN ISP that can be used to input the program into the KK Board V 2.0 Flight Controller. There are 5 input data that will be used by KK Board V 2.0 to be able to control the Quadcopter Flying vehicle those are the Elevator data for forward and backward control, Aileron data for left and right control, Throttle data for up and down (as gas pedal), Ruddler data for control the Quadcopter to be able to move in horizontal rotation and Aux data to activate the Self Balancing function from KK Board in order that the Quadcopter will be able to stabilize itself when there was disturbance from outside factor. In this KK Board, the user can set manual constantan PI for Self Balancing form the Quadcopter according to its dimension and weight.

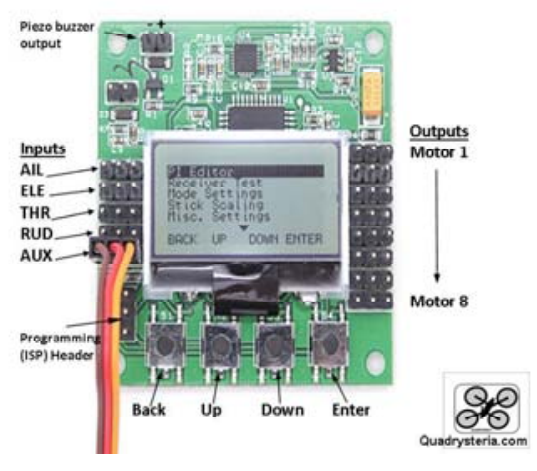

Figure 1. Configuration of Socket KK Board V 2.0 [3]

\subsection{Electronics Speed Controller}

ESC (Electronic Speed Controller) on Figure 2 has function as a motor speed controller; beside it also has function to increase the amount of current needed by motor. ESC can be also called as motor driver by producing pulse for brushless motor that came from the micro-controller.

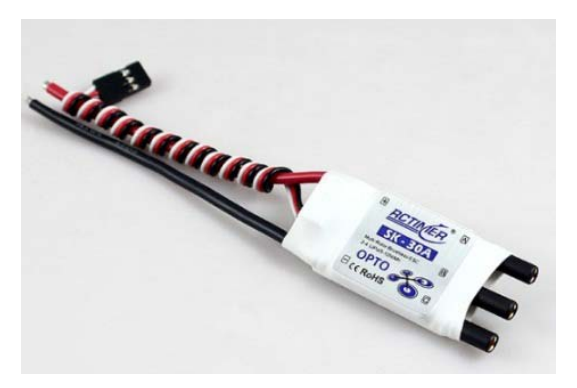

Figure 2. Electronic Speed Controller [4] 


\subsection{Brushless Motor}

Brushless motor on Figure 3 is a motor that has permanent motor on the rotor part, while the electromagnet on the stator part. Generally, the speed of brushless motor rotation produced by ESC was arranged by the pulse from the micro-controller, so it is different from brushed [5], [6]. BLDC motor or can also be called as BLAC motor, is a synchronous electric motor AC phase 3. The differentiation in naming is due to BLDC that has BEMF with trapezoid shape while the BLAC has BEMF with sinusoidal shape. Eventhough, both have the same structure and can be controlled by using six-step method or PWM method. To be compared with other DC motor types, the BLDC has lower maintenance cost and higher speed because it uses no brush. To be compared with induction motor, the BLDC has higher efficiency because the rotor and initial torsion produced made of permanent magnet.
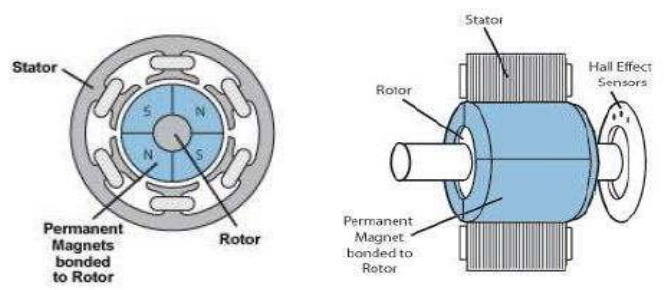

Figure 3. Brushless Motor [7]

\subsection{Propeller}

The propeller on Figure 4 is a type of fan that produces power by converting rotation movement into impetus to move a thing. The blades of the propeller has function as rotating wings that produce a difference of pressure between the frontside and the backside of the blade. Propeller is devided into two types those are $\mathrm{CW}$ and $\mathrm{CCW}$.

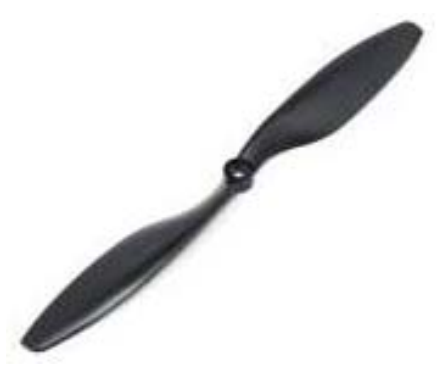

Figure 4. Propeller

\subsection{PID Control System}

In a control system there are some control actions, among others the proportional control action, integral control action, and the derivative control action. Each of control action has certain superiority, where the actions are as the following:

1. The proportional control action has quick risetime superiority.

2. The integral control action has superiority to minimize error.

3. The derivative control action has superiority to minimize error or to muffle overshot/undershot.

General characteristic to be used in the controlling of a system among others include the stability, accuracy, respond speed and sensitivity. In the action of proportional control, output of the control system always proportional with the input. Output signal is an amplification of an error signal with certain factor; this amplification factor is a proportional constantan of the system, that is stated with Kp, where this Kp has high and quick respond. In integral control action, output of this controller always change during deviation occur, and the output change speed is proportional with its deviation, the constantan is stated in $\mathrm{Ki}$, where this $\mathrm{Ki}$ has high sensitivity, that is by the method of reducing error produced from feedback signal. The greater $\mathrm{Ki}$ value, the higher its sensitivity, but time needed to reach the stability is faster, so thus in the contrary. Whereas the derivative control action works based on the deviation change rate, so this controller 
type is always used together with the proportional and integral controller, the constantan is stated as $\mathrm{Kd}$, where this $\mathrm{Kd}$ influence the stability of the system, because this action can reduce error [8]. Figure 5 is a diagram block of the PID control system with close loop.

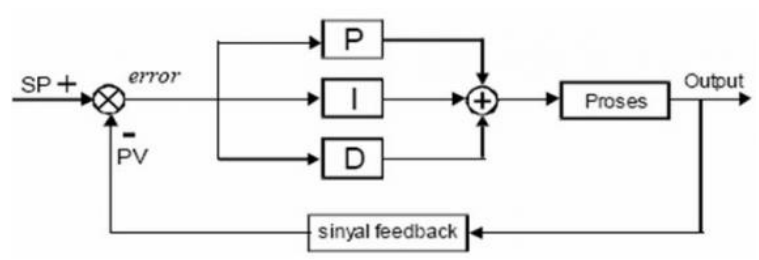

Figure 5. Block Diagram of PID Control System [8]

\subsection{The GoPro HD Hero2 Camera}

The GoPro HD Hero2 camera on Figure 6, with dimension of 3.9 x 3.9 x 9.6", and lens that has power of $11 \mathrm{mp}$ can perform to take 10 pictures only in 1 second, or more sophisticated by using 'TimeLapse' mode that produces 1 shot only in 0.5 second. Figure shooting can be done quickly with very fine picture quality. This is because it is completed with special lens on the frontside in order it will not have disturbance at the time of picture shooting.

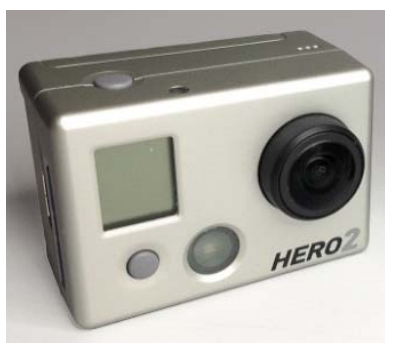

Figure 6. GoPro Camera hero2

\subsection{Sender SkyZone $5.8 \mathrm{G} 400 \mathrm{~mW}$ video}

Sender SkyZone $5.8 \mathrm{G} 400 \mathrm{~mW}$ video is a communication device that is used to send data in the form of Audio Video with maximum distance of 5 kilometers with line of side condition. Figure 7 and Figure 8 show the Transmitter and Receiver.

The specifications of the Audio Video Transmitter are as the following:

1. It has 8 channels that can be used.

2. It works on the Frequency Channel from $5645 \mathrm{Mhz}$ to $5945 \mathrm{Mhz}$.

3. Video format that can be supported is the NTSC/PAL.

4. Operation voltage $=\mathrm{DC} 7 \mathrm{v}$ to $14 \mathrm{v}$.

5. Current consumption $=220 \mathrm{~mA}$.

6. Type of connector antenna is RP-SMA.

7. Dimension $=55 \times 26 \times 17 \mathrm{~mm}$.

8. Weight $=25 \mathrm{gr}$. 


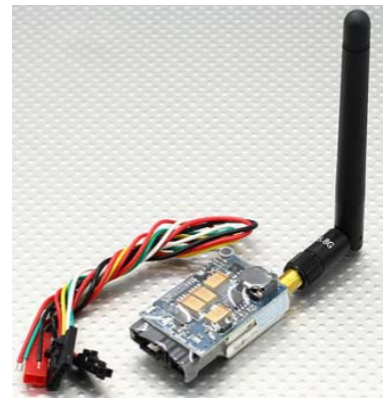

Figure 7. Video Sender Transmitter (Tx)

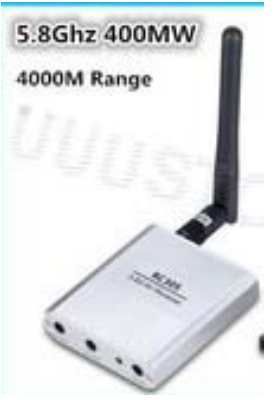

Figure 8. Video Sender Recivier (Rx)

\section{RESEARCH METHOD}

Design method of quadcopter robot consists of quadcopter 3D design and hardware design of quadcopter robot. On the design of the quadcopter, it also calculates all aspects that can influence the performance of the quadcopter. On the hardware design it consists of some parts those are:

1. Mehanical design of quadcopter robot.

2. Electronic system design.

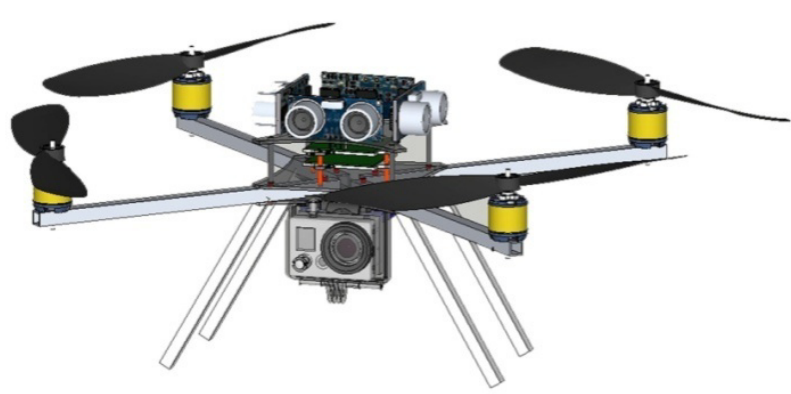

Picture 9. Is a design of quadcopter robot

Picture 10 is a diagram block of electronic system of the quadcopter robot.

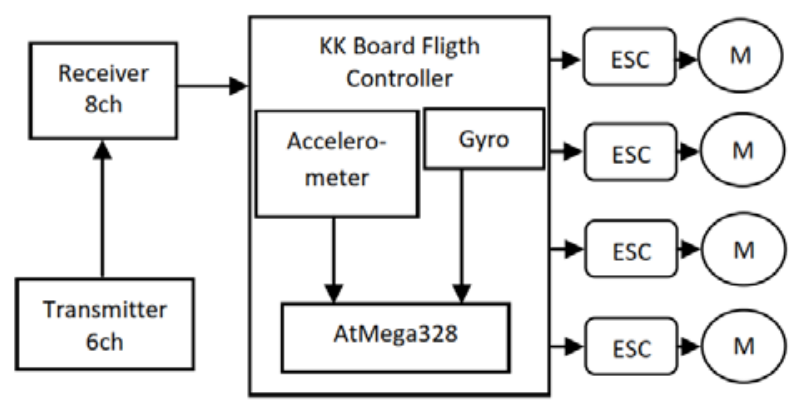

Figure 10. Block Diagram Electronic Systems Quadcopter

On Figure 11 shows that the remote control gives order signal to quadcopter robot, then the camera installed on the quadcopter will send information in the form of video and audio to laptop by using video sender device. 


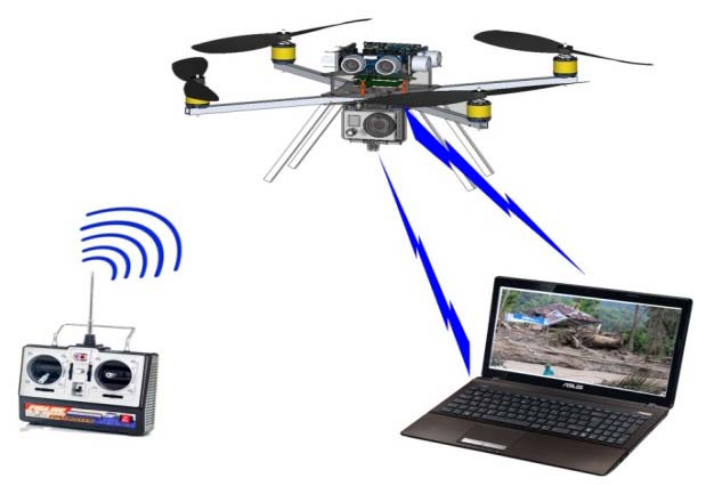

Figure 11. Illustration of Work Systems Quadcopter

\section{RESULTS AND ANALYSIS}

\subsection{Realization of Design Result of the Quadcopter Robot Hardware}

Assembling process of quadcopter robot was started by the assembling of robot's frame and safety blade. Afterwards to be continued by installing electronic system wiring, like it is seen in Figure 12 and Figure 13.

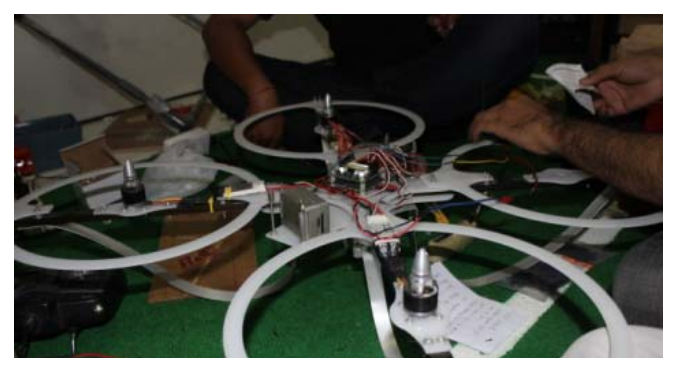

Figure 12. assembly process Quadcopter Robot

Realization of design result of quadcopter robot that has been completed with GoPro Hero 2 camera.

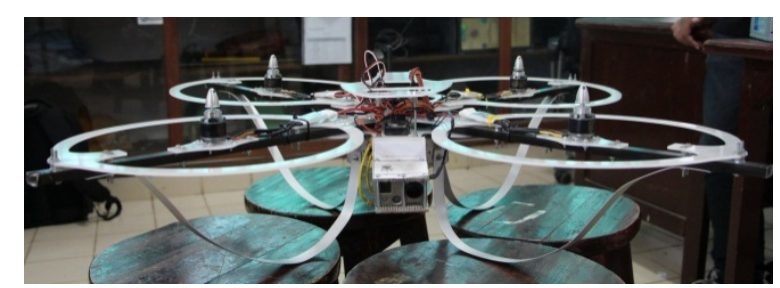

Figure 13. Actual Results Design

\subsection{PWM Signal Testing}

This testing has purpose to find out pulse wide of each controller signal that was inputted to KK board Flight controller from the receiver. This testing used oscilloscope to show pulse wide from each inputs. Inputs meant are the Aileron, Elevator, Throtle, Rudder, and Auxilary. The PWM testing result can be seen in Figure 14. 

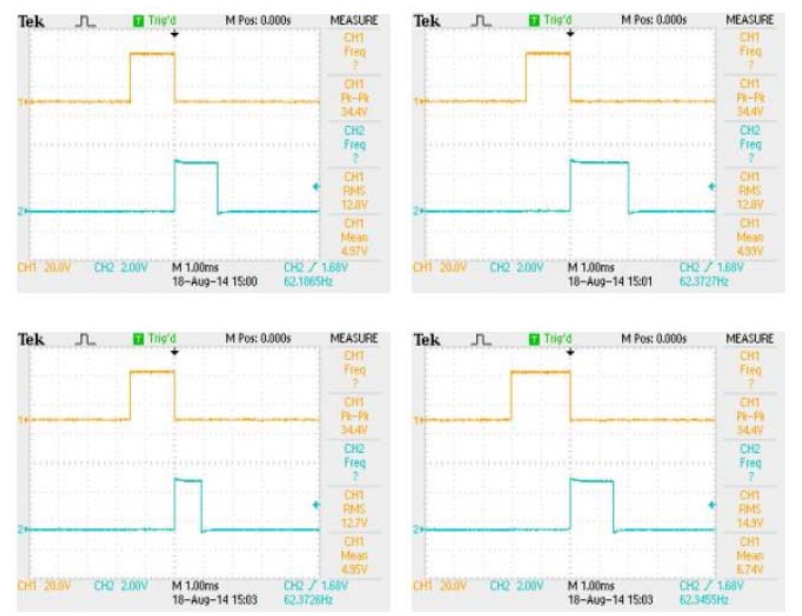

Figure 14. Signal Testing Elevator and Aileron

\subsection{Lift Power Testing of Quadcopter Robot}

Lift power testing from the combination of motor and blade that is used to quadcopter robot has function to find out how much maximum load that can be given to the quadcopter in order to be able to fly properly. Based on the previous testing result, weight of the quadcopter this time is $4.2 \mathrm{~kg}$. In Figure 15 it can be seen the lift power testing of the motor and blade combination used in the quadcopter. Testing result obtained that lift power of the motor and blade combination used is $1.1 \mathrm{~kg}$. In that case, for quadcopter with four motors and blades will be able to lift load for $4.4 \mathrm{~kg}$. This time, quadcopter weight is $4.2 \mathrm{~kg}$, so it still is able to be given more loads for about $0.2 \mathrm{~kg}$.

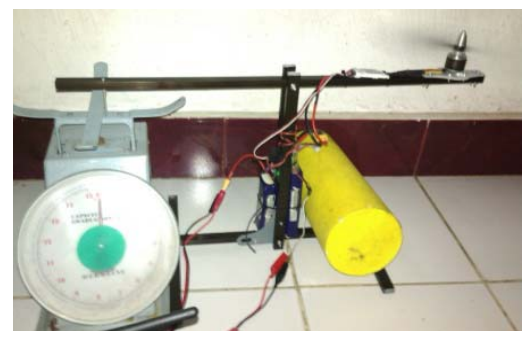

Figure 15. Testing of Power Lift from Quadcopter Robot

\subsection{RPM (Rotation Per-Minute) Testing and Calculation of Power of Brushless Motor}

The RPM (Rotation Per-Minute) Testing of this brushless motor has purpose to find out the amount of rotation that can be performed by brushless motor, because RPM produced from this brushless motor strongly related to power consumption performed. Whereas diagram block of RPM testing of this brushless motor is as the following:

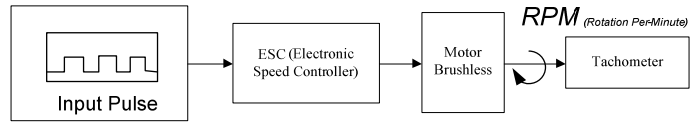

Figure 16. Block Diagram RPM Testing

From the diagram block on Figure 16 it can be explained that the rotation speed from the brushless motor depends to PWM (Pulse Width Modulation) amount given. To be able to measure RPM from brushless 
motor, it uses measurer that is tachometer. Figure 17 shows the process of RPM testing from brushless motor on the quadcopter robot.

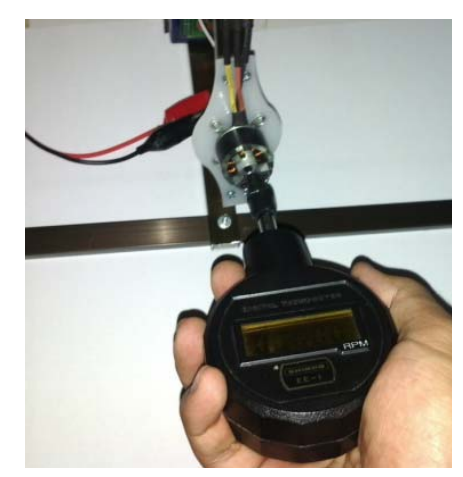

Figure 17. RPM Testing Process

Table 1 is result of RPM (Rotation Per-Minute) testing to brushless motor.

Table 1. Result of RPM Testing

\begin{tabular}{ccc}
\hline No & PWM Throttle Pulse Given & $\begin{array}{c}\text { Motor Rotation } \\
\text { (RPM) }\end{array}$ \\
\hline 1 & & 0 \\
2 & $0 \%$ & 3204 \\
3 & $25 \%$ & 6662 \\
4 & $50 \%$ & 11592 \\
5 & $75 \%$ & 13068 \\
\hline
\end{tabular}

From the testing result it can be concluded that the maximum RPM (Rotation Per-Minute) from brushless motor used is \pm 13.068 RPM. Power consumption from brushless motor used can be calculated refering to data on the datasheet from the brushless motor.

- Motor Specification:

$\begin{array}{ll}\text { Model } & : \text { NTM Prop Drive Series 28-26A } \\ & 1200 \mathrm{kv} \\ \mathrm{Kv} & : 1200 \mathrm{rpm} / \mathrm{v} \\ \text { Current } & : 1 \mathrm{~A} / 765 \mathrm{rpm} \\ \text { Max current } & : 18 \mathrm{~A} \\ \text { Max Power } & : 216 \mathrm{~W} @ 12 \mathrm{v}(3 \mathrm{~S}) \\ \text { Shaft } & : 3 \mathrm{~mm} \\ \text { Weight } & : 57.6 \mathrm{~g}\end{array}$

*note : Kv stated constant motor speed measured in RPM per volt.

From the motor specification data, to obtain power used in motor, the maximum voltage and current from the motor can be obtained based on the maximum RPM produced by motor obtained from the previous testing. The following is the calculation process about power used by brushless motor to obtain maximum RPM:

RPMmax $=13068 \mathrm{rpm}$

Voltage needed by motor to reach maximum RPM (13068rpm) is:

$\mathrm{Vm}=13068 \mathrm{rpm} / 1200(\mathrm{rpm} / \mathrm{V})=10.89$ Volts

Voltage Source $(\mathrm{Vs})=11.1$ Volts (in condition that motor has not been loaded)

Drop Voltage $=\mathrm{Vs}-\mathrm{Vm}=11.1-10.89=0.21$ Volts

Current needed by motor for maximum RPM (13068 rpm) is:

$\operatorname{Im}=13068 \mathrm{rpm} \times(1 \mathrm{~A} / 765 \mathrm{rpm})=17.08 \mathrm{~A}$

* Maximum Current from ESC (Electronic Speed Controller): 20A

From the calculation of current and voltage then Power needed by motor to reach maximum RPM is:

Pmotor $=$ Vm x Im $=10,89 \mathrm{~V} \times 17,08 \mathrm{~A}=186,0012 \mathrm{Watt} 186 \mathrm{Watt}$ 


\subsection{Testing of the Quality of Camera Figure Sending by Using Video Sender 5.8 G 400mW}

On the testing of picture sending from GoPro Hero 2 camera to Television screen by using Video Sender 5.8G it will exposed by using table of result of distance testing and result of picture received on the television, as shown on Table 2. This testing was performed in the Laboratory of Control Technique of Electro Technique Study Program of Technique Faculty of Udayana University Bukit Jimbaran Campus.

Table 2. Result of Figure Quality Testing

\begin{tabular}{llll}
\hline No & $\begin{array}{c}\text { Distance of Tx } \\
\text { and Rx (Meter) }\end{array}$ & \multicolumn{1}{c}{ Condition } & \multicolumn{1}{c}{$\begin{array}{c}\text { Description of } \\
\text { Figure Quality }\end{array}$} \\
\hline $\mathbf{1}$ & 1 & Line of side & Very fine \\
$\mathbf{2}$ & 5 & Line of side & Fine \\
$\mathbf{3}$ & 10 & Line of side & Fine \\
$\mathbf{4}$ & 10 & Wall bound & Picture blurred \\
$\mathbf{5}$ & 15 & Line of side & Fine \\
$\mathbf{6}$ & 15 & Different story & Loss \\
$\mathbf{7}$ & 50 & Line of side & Fine \\
$\mathbf{8}$ & 100 & Line of side & Fine \\
$\mathbf{9}$ & 100 & Tree bound & Blurred \\
$\mathbf{1 0}$ & 300 & Line of side & Fine \\
$\mathbf{1 1}$ & 500 & Line of side & Fine \\
\hline
\end{tabular}

\subsection{Result of Outdoor Testing}

This testing was performed on an empty area near the enter gate of Jimbaran campus. The outdfoor testing performed has purpose to take surrounding's traffic picture, as shown on Figure 18 and Figure 19.

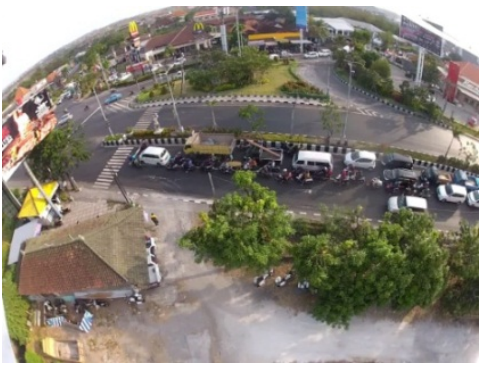

Figure 18. Observations Traffic Traffic Intersection Jimbaran

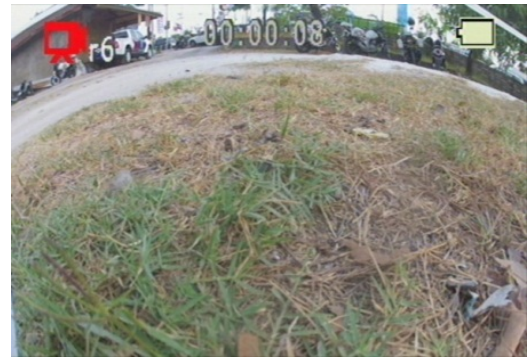

Figure 19. Display Stream GoPro Camera Before Airing

Picture 20 and Figure 21 shows the streaming appearance of GoPro camera by using laptop. Result of live picture from GoPro camera with result of streaming picture has a different quality. Streaming picture resulted has very poor quality, because the delivered picture has passed compression phase performed by Video Sender Tx. There is delay time lapse of information sending with time interval of 0.5 second.

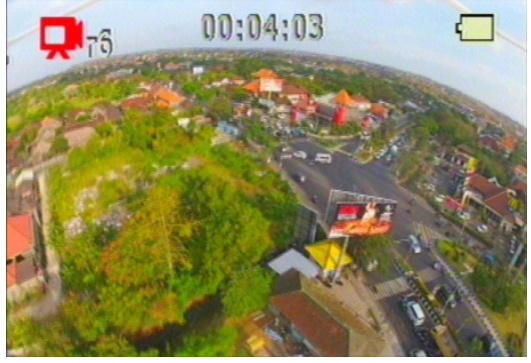

Figure 20. Display Stream GoPro camera while in the air

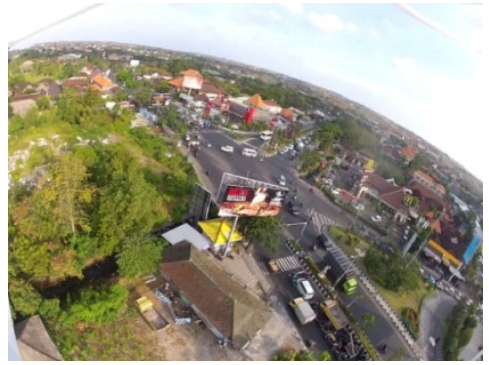

Figure 21. Maximum Height 30 meters On When Testing 


\section{CONCLUSION}

The conclusions that can be drawn from the discussion performed are as the following:

1. Generally, the communication to control the movement of quadcopter robot using remote control and controller KK board V 2.0 has worked properly, where the controlling of movement of this quadcopter robot include the movement of forwards, backwards, left, and right which were performed outdoor.

2. Testing of information delivery in the form of picture from the Go Pro Hero 2 camera used the video sender media has worked properly if between Tx and Rx video sender are face to face (not bound by building). Distance can be reached is maximum for 500 meter. Result of video streaming has time lapse for 0.5 second.

3. Maximum RPM (Rotation Per-Minute) that can be produced from brushless motor NTM Prop Drive Series 28-26A $1200 \mathrm{kv}$ used on quadcopter is $13.068 \mathrm{rpm}$ with power needed is for 186 watt.

4. Maximum lift power that can be produced by quadcopter by using brushless motor NTM Prop Drive Series $28-26 \mathrm{~A} 1200 \mathrm{kv}$ and propeller sized $11 \mathrm{x} 4.7 \mathrm{~cm}$ is for $4.4 \mathrm{~kg}$.

\section{ACKNOWLEDGEMENTS}

I would like to express my very great appreciation to goes to research team and colleague who has made valuable contributions in this study and their critical comments on this manuscript.

\section{REFERENCES}

[1] Engel, J. 2011. Autonomous Camera-Based Navigation of a Quadcopter. Jerman: (Thesis) Universitas Munchen Jerman.

[2] Zhang L., Zhang T., Wu H., Borst A., Kuhnlenz K. 2012. Visual Flight Control of a Quadcopter Using Bioinspired Motion Detector. Jerman: International Journal of Navigation and Observation. Vol. 2012.

[3] Bakke, R.R. 2014. KK 2.1 Multi-Rotor Control Board [cited 2014 September 6]. Avaible From: URL ; www.hobbyking.com

[4] SimonK. 2014. ESC 20A OPTO [cited 2014 September 6]. Avaible From : URL; www.rctimer.com

[5] Oriental Motor General Catalog. 2010a. Motor Brushless. [cited 2013 November 8 ]. Avaliable From : URL; www.orientalmotor.com

[6] Oriental Motor General Catalog. 2010b. Wiring Diagram Motor Brushless. [cited 2013 November 8 ]. Avaliable From: URL; www.orientalmotor.com.

[7] Hobby King. 2014. NTM Prop Drive [cited 2014 September 6]. Avaible From : URL; www.hobbyking.com

[8] Ogata, K. 1994.Teknik Kontrol Automatik Jilid 1. Jakarta: Erlangga. 